\title{
DISCURSO DEL DR. JESUS ALBERTO GOMEZ PALACINO \\ AL RECIBIR EL PREMIO DE LA \\ ACADEMIA NACIONAL DE MEDICINA
}

Señor Doctor

JORGE GARCIA GOMEZ

Ministro de Salud

\section{Señor Doctor}

HERNANDO GROOT

Presidente de la Academia Nacional de Medicina

\section{Señor Doctor}

ROBERTO GARCIA ROJAS

Gerente General de Salvat Editores

\section{Señoras, Señores:}

No será en esta ocasión cuando diga que hemos descubierto la causa de la Toxemia Gravídica, pero sí puedo afirmar, con seguridad, que el escudo en blanco para ser llenado con el nombre de quien la descubra, $y$ que reposa en el pórtico del "Chicago Lying-in Hospital" permanecerá así hasta cuando aceptemos que la Enfermedad Hipertensiva del Embarazo no tiene una causa sino que aparece como consecuencia de múltiples factores etiológicos.

Concedido así el problema, será preciso aceptar también que cada paciente tiene su Toxemia y que al lado de la enferma para quien su embarazo ha significado un grave problema psicoemocional, manifestado clínicamente por los signos y síntomas propios del estres, puede estar aquella cuyos complejos inmunogenéticos no han sido propicios; que junto a la enferma que en la sala del hospital está convulsionando porque su abdómen está sobredistendido a causa de un embarazo gemelar, puede estar la adolescente famélica que todo lo ha ignorado.

Si lo anterior es así, la patogenia de la enfermedad será para cada paciente diferente y también debería serlo su manejo y tratamiento. $\mathrm{Ha}$ perdido entonces, para nosotros, la enfermedad su carácter enigmático en la medida en que la investigación ha reemplazado la especulación, que por encima de los hechos demostrados, la imaginación humana había creado. Si hemos llegado a las conclusiones anteriores, y si decimos además que en 1953 en el Instituto Materno Infantil de Bogotá, de cada 100 mujeres con Eclampsia 25 fallecían, y de cada 100 posibles hijos vivos sucumbían 45 y que en 1978 estas cifras se habían reducido a 3 y a 20 respectivamente, más de 20 años dedicados al estudio de la Toxemia no han sido vanos, pero tampoco suficientes. Es el momento de afirmar que si bien es cierto el problema está parcialmente resuelto en el aspecto terapéutico intrahospitalario, falta emprender la tarea que conduzca a la prevención y control de la enfermedad Nuestro país ocupa en Latinoamérica uno de los primeros lugares en cuanto 
a la incidencia de la enfermedad, tan solo superada por Paraguay y Trinidad Tobago. Si aceptamos que tal índice es el reflejo de la eficacia de las campañas de protección materno-infantil, tenemos que reconocer que hay un largo camino por recorrer.

Comprometidos entre los factores predisponentes de la enfermedad la ignorancia, la falta de control prenatal, la desnutrición, y ligados a ellas los escasos recursos económicos, será imperioso buscar las soluciones sin descartar en ellas las de carácter político que corrijan las desigualdades existentes y que inciden directamente sobre las tasas de mortalidad. Sociólogos, demógrafos, salubristas, epidemiólogos, deberán sumarse a los estudios y campañas a emprender.

La enfermedad Hipertensiva del Embarazo continúa siendo una de las primeras causas de mortalidad materna en un país en donde, según informe oficial de 1980 al Congreso de la República, las complicaciones del embarazo constituyen la primera causa de atención hospitalaria con cerca del $40 \%$ de todos los egresos entre 1969 y 1979 . Además, y de acuerdo con los datos suministrados por el Departamento Nacional de Estadística, en el período comprendido entre 1972 y 1977 fallecieron en Colombia 1.293 mujeres a causa de la Toxemia Gravídica, cifra que contrasta con lo ocurrido en Inglaterra en donde hubo en el trienio 1970 - 1972 solamente 29 decesos.
El panorama es más sombrío cuando se analizan los efectos de la entidad sobre la descendencia pues sigue siendo la primera causa de mortalidad perinatal $y$ además los niños que sobreviven pueden llevar consigo, y para siempre, las secuelas de la enfermedad.

De todo lo anterior se concluye que la Toxemia Gravídica no puede seguir siendo patrimonio exclusivo de los obstetras sino que sus múltiples facetas escondidas deberán ser objeto de investigación y estudio por parte de inmunólogos, pedíatras, hematólogos, nefrólogos, endrocrinólogos, nutricionistas, neurólogos y psiquiatras, para no mencionar sino algunas de sus compleias áreas de estudio. A todos ellos está dedicado el mensaje que esta noche ha sido generosamente calificado. Estoy seguro de que será aprovechado, para que en un futuro no lejano podamos hacerles a los Colombianos, empleando las palabras de Pio Baroja cuando a comienzos del siglo se refería a las gentes pobres de los suburbios de Madrid, menos áspera la vida.

Señores Miembros de la Academia Nacional de Medicina, Señores Repre. sentantes de Salvat Editores: Ustedes me han dado la oportunidad de servir à mi Patria, muchas gracias.

\section{Jesús Alberto Gómez Palacino}

